\title{
Cholinergic Treatments with Emphasis on M1 Muscarinic Agonists as Potential Disease-Modifying Agents for Alzheimer's Disease
}

\author{
Abraham Fisher \\ Israel Institute for Biological Research, P. O. Box 19, Ness-Ziona 74100, Israel
}

\begin{abstract}
Summary: The only prescribed drugs for treatment of Alzheimer's disease (AD) are acetylcholinesterase inhibitors (e.g., donepezil, rivastigmine, galantamine, and tacrine) and memantine, an NMDA antagonist. These drugs ameliorate mainly the symptoms of $\mathrm{AD}$, such as cognitive impairments, rather than halting or preventing the causal neuropathology. There is currently no cure for $\mathrm{AD}$ and there is no way to stop its progression, yet there are numerous therapeutic approaches directed against various pathological hallmarks of AD that are extensively being pursued. In this context, the three major hallmark characteristics of AD (i.e., the CNS cholinergic hypofunction,
\end{abstract}

formation of $\beta$-amyloid plaques, and tangles containing hyperphosphorylated tau proteins) are apparently linked. Such linkages may have therapeutic implications, and this review is an attempt to analyze these versus the advantages and drawbacks of some cholinergic compounds, such as acetylcholinesterase inhibitors, M1 muscarinic agonists, M2 antagonists, and nicotinic agonists. Among the reviewed treatments, M1 selective agonists emerge, in particular, as potential disease modifiers. Key Words: Alzheimer's, cholinergic, $\beta$-amyloid, tau, acetylcholinesterase inhibitors, M1 muscarinic, nicotinic, agonists, M2 muscarinic antagonists.

\section{INTRODUCTION}

Alzheimer's disease (AD) is a progressive, neurodegenerative disease that is a major health problem in modern societies. AD is characterized by memory and cognitive loss, synaptic loss, amyloid plaques containing the $\beta$-amyloid peptide $(\mathrm{A} \beta)$, degeneration of cholinergic neurons that ascend from the basal forebrain to cortical and hippocampal areas, and neurofibrillary tangles (NFT). ${ }^{1}$ In spite of extensive research performed in the last decades there is no clear proof as to the etiology of $\mathrm{AD}$.

One of the major hallmarks of $\mathrm{AD}$ is the amyloid plaque. The key component of the amyloid plaque core is the deposited $\mathrm{A} \beta$, which is derived from the amyloid precursor protein (APP). The APP is cleaved by at least three sites, $\alpha-, \beta$-, and $\gamma$-secretase cleavage. ${ }^{1-8}$ The APP through an enzymatic activity termed $\alpha$-secretase, precludes formation of $\mathrm{A} \beta$ and generates a cell-associated $\mathrm{C}$-terminus (C83) fragment and a longer secreted form

Address correspondence to: Abraham Fisher, Ph.D., Israel Institute for Biological Research, P. O. Box 19, Ness-Ziona 74100, Israel. E-mail: fisher_a@netvision.net.il; fisher_a@iibr.gov.il.
( $\alpha$-APPs) that is neurotrophic and neuroprotective. In an alternate pathway, $\beta$-secretase (BACE1) cleaves APP releasing a large secreted derivative $\operatorname{SAPP} \beta$ and a Cterminal fragment C99 that can be further cleaved by $\gamma$-secretase to form $\mathrm{A} \beta$, which is released into the extracellular milieu. The predominant peptide secreted is $\mathrm{A} \beta 40$ with approximately 10 to $15 \%$ being $\mathrm{A} \beta 42$, the more toxic specie. The $\mathrm{A} \beta$ peptide, in particular $\mathrm{A} \beta 42$, aggregates and is part of the plaque core. The "amyloid cascade hypothesis," and variations thereof, postulate that generation of $\mathrm{A} \beta$, its oligomers, and their accumulation in the brain, and finally their deposits in plaques is the major culprit that leads to $\mathrm{AD}^{8,9}$; also see further references on this. ${ }^{10,11}$ In this context, the current notion is that blocking $\mathrm{A} \beta$ formation and/or deposition into plaques should prevent the progression of $\mathrm{AD}$, but it does not, however, reverse the damage already caused. ${ }^{12}$

Another major hallmark of AD is a cholinergic hypofunction evidenced by a reduction in acetylcholine (ACh) synthesis due to reduced choline acetyltransferase (ChAT) and choline uptake, cholinergic neuronal, and axonal abnormalities, with degeneration of cholinergic neurons projecting to the cortex and hippocampus, and significant depletion of the nicotinic receptors. ${ }^{1,12,13-18}$ 
Central cholinergic deficits have a major role in the progressive cognitive dysfunction, as well as some behavioral impairment associated with $\mathrm{AD}$. In this context, the loss of presynaptic cholinergic markers correlates with the number of plaques, NFT, and clinical severity of dementia. ${ }^{17}$ The rationale for cholinergic treatment in $\mathrm{AD}$ is based on the "cholinergic hypothesis," which suggests that cholinergic hypofunction contributes to many of the cognitive and behavioral deficits in patients with AD. ${ }^{2,14,15}$ This hypothesis prompted the development of treatment strategies aimed to restore lost cholinergic function and to ameliorate cognitive and behavioral impairments in $\mathrm{AD}$ patients. The increase in $\mathrm{A} \beta$ formation and cholinergic dysfunction may occur long before overt cognitive or behavioral symptoms of AD are detectable, and both may be implicated as causal factors in AD. However, it is beyond the scope of this review to debate which culprit is the earliest causal factor for inducing AD.

A third major hallmark of AD is the NFT comprised of hyperphosphorylated tau proteins. Tau proteins are normally expressed in axons as microtubule associated tau proteins, which stabilize microtubules, allowing fast axonal transport. ${ }^{7,17,19,20}$ The "tau hypothesis" is based on the abnormal state of tau proteins in $\mathrm{AD}$ that is both highly phosphorylated and aggregated into paired helical filaments in NFTs. ${ }^{17,19,21}$ When tau proteins are hyperphosphorylated, there is a breakdown in the system; preventing tau hyperphosphorylation and aggregation can decrease formation of NFTs. The formation of NFT contributes to $\mathrm{AD}$, but it is debatable whether it is the earliest causal factor underlying $\mathrm{AD}$ pathogenesis as $\mathrm{A} \beta$ plaques typically occur before NFTs.

Notably, a relationship between three of the major hallmarks that are characteristic of $\mathrm{AD}$ have been reported: 1) the CNS cholinergic hypofunction, 2) formation of $\mathrm{A} \beta$ plaques, and 3 ) tangles containing hyperphosphorylated tau proteins. ${ }^{17,20,22-26}$

The existing drug therapy mainly targets the symptoms of $\mathrm{AD}$, such as cognitive impairments, rather than also halting or preventing the causal neuropathology. The only approved drugs for the treatment of $\mathrm{AD}$ by many national regulatory authorities, including the Food and Drug Administration in the United States, are acetylcholinesterase (AChE) inhibitors (AChE-Is) (e.g., donepezil, rivastigmine, galantamine and tacrine), ${ }^{13,27-32}$ and memantine, which is an NMDA antagonist. ${ }^{14}$

This review will present some of the published cholinergic therapeutic strategies vis-a-vis the major hypotheses as to the causes of AD. However, due to the plethora of treatments advocated in the last few years (several of them at an early stage of drug discovery), the review can not cover all the published cholinergic treatments. Some potential advantages and possible challenges in the reviewed therapies are discussed. This review will also address the question of how the three major hallmarks that characterize $\mathrm{AD}$ (e.g., cholinergic hypofunction, $\mathrm{A} \beta$, and neurofibrillary tangles) may relate to each other, and how these findings can be translated into comprehensive and viable modern therapies.

\section{SELECT TREATMENT STRATEGIES BASED ON THE CHOLINERGIC HYPOTHESIS}

\section{AChE-Is}

The AChE-Is act on the ACh pathway by inhibiting the enzyme AChE, which is normally responsible for hydrolysis of ACh. These AChE-Is, in spite of some limitations (see as follows), still represent the primary treatment available for $\mathrm{AD}$ and related forms of dementia. ${ }^{13,27-32}$

The effects of the four prescribed AChE-Is on improvement of cognition in $\mathrm{AD}$ patients is similar, yet the compounds differ to a certain extent in mechanism of action, in terms of side effects (SE) and treatment schedules. Notably, while donepezil is mainly selective for $\mathrm{AChE}$, rivastigmine and tacrine inhibit both $\mathrm{AChE}$ and butyrylcholinesterase (BuChE) and galantamine, in addition to its inhibitory effect on $\mathrm{AChE}$, is a putative allosteric activator of the nicotinic receptor (e.g., $\alpha 4 \beta 2$ subtype). ${ }^{13,27-31}$ In general, these drugs have demonstrated a statistically significant effect versus placebo on cognitive, global, and functional performance of patients with $\mathrm{AD}$, but tacrine is rarely used because it can cause liver problems. Notably, the drugs (and their most frequent SE) observed include: tacrine (hepatotoxicity and gastrointestinal effects); donepezil (nausea, vomiting and diarrhea); rivastigmine (nausea, vomiting, diarrhea, and anorexia); and galantamine (nausea, vomiting, diarrhea, and anorexia). It is beyond the scope of this review to elaborate on these treatments because numerous reviews have been written on this subject. ${ }^{13,27-32}$

The use of AChE-Is in AD patients is regarded mainly as a symptomatic treatment without significant effect on disease progression. In this context, the progression of the disease associated with loss of the cholinergic neurons and decreases in ACh may limit the therapeutic potential of this treatment strategy to only part of the $\mathrm{AD}$ patients. AChE-Is may also appear to stabilize the course of $\mathrm{AD}$ progression to a certain extent. ${ }^{28}$ Several longterm clinical trials with AChE-Is have reported that these drugs actually decrease the rate of cognitive decline, and may delay the disease progression by 1 to 2 years, ${ }^{28,31}$ but the benefits are modest. ${ }^{31}$ It was also recently reported that AChE-Is are unable to slow progression from mild cognitive impairment to dementia. ${ }^{33}$

In addition to the Food and Drug Administration-approved AChE-Is, several other such inhibitors at various stages of research and development have been reported. These include compounds such as: phenserine, ${ }^{34,35}$ 
CHF2819, ${ }^{36}$ TAK $147,{ }^{37}$ TV3326, ${ }^{38}$ huperzine A and analogs, ${ }^{39}$ NP-61, ${ }^{40}$ and Memoquin. ${ }^{41}$ Preclinical studies showed that some of these newer AChE-Is may have additional properties versus the existent AChE-Is prescribed drugs that may enhance their putative therapeutic value in $A D$ treatment. In fact, the new generation of AChE-Is can be defined as multifunctional compounds designed to provide effects, such as neuroprotection, intervention in $\mathrm{A} \beta$ processing, and others, in addition to inhibition of AChE. Although this approach, in principle, may provide more effective drugs, some of the multifunctional compounds (defined as "dirty drugs") can also display multiple SE contributed by each respective mechanism alone or acting in concert.

Selective inhibitors of BuChE were suggested as a potential treatment for $\mathrm{AD}$ based on the rationale that $\mathrm{BuChE}$ levels are increased in $\mathrm{AD}$ brains and that some neuronal pathways may function through $\mathrm{BuChE}{ }^{42} \mathrm{It}$ remains to be seen if BuChE inhibitors will have less SE and will be superior versus the approved AChE-Is. Notably there is no clear evidence that rivastigmine, a dual AChE-Is and BuChE inhibitor, is more effective than donepezil (selective AChE-Is) in AD patients.

\section{M1 muscarinic agonists}

$\mathrm{AD}$ appears mainly to be a presynaptic cholinergic hypofunction, whereas post-synaptic M1 muscarinic receptors (M1 mAChR) are relatively unchanged. ${ }^{17,43-47}$ Postsynaptic M1 muscarinic receptors (M1 mAChR), predominant in cerebral cortex and hippocampus, have a major role in hippocampal-based memory and learning regulation of cognition and psychosis, and short-term memory in particular, which is impaired in AD. ${ }^{17,43-47}$ The rationale for developing M1 muscarinic agonists as a potential treatment strategy in $\mathrm{AD}$ is based on "the cholinergic hypothesis," the status of M1 mAChR, and the linkage between the three neuropathological hallmarks of $\mathrm{AD} .^{22,23,43-48} \mathrm{M} 1$ selective muscarinic agonists may, in principle, be more beneficial in treating $\mathrm{AD}$ than AChE-Is, because such agonists should be less affected by the extent of degeneration of presynaptic cholinergic terminals capable of synthesizing and releasing the neurotransmitter ACh.

While activation of M1 mAChR is advantageous, stimulation of the other mAChR subtypes leads to SE. ${ }^{22,23}$ Therefore, M1 muscarinic agonists should be devoid of M2, M3, and M5 agonistic effects to minimize SE. Some muscarinic agonists improved cognition and reduced psychotic episodes in AD patients. ${ }^{22,23}$ However, a scarcity of selective M1 muscarinic agonists has limited the clinical use of muscarinic agonists in $\mathrm{AD}$ due to $\mathrm{SE}$ observed at higher doses, and thus most of the muscarinic agonists tested in $\mathrm{AD}$ patients had pharmaceutical disadvantages. ${ }^{22,23}$ Another potential drawback in the use of muscarinic agonists may be a possible downregu- lation of M1 mAChR, if continuously stimulated by agonists. Such a disadvantage may be evident with full, but not partial, agonists. In addition to the drawbacks previously mentioned, the clinical testing of muscarinic agonists in $\mathrm{AD}$ patients was governed by pharmacokinetic rather than pharmacodynamic considerations, leading to overdosing and SE that may have actually obscured beneficial clinical effects of tested muscarinic agonists. Notably, most preclinical studies that showed significant efficacy in restoring cognitive dysfunctions using single, daily administration of the tested muscarinic agonist, regardless of its plasma half-life, M1 mAChR selectivity, full or partial agonistic, and/or SE profiles. Furthermore, long-term effects on cognition in preclinical studies were detected with such compounds after the compounds were eliminated from the body. ${ }^{22,23}$ These would indicate that lower and less frequent dosing with an M1 muscarinic agonist may still be effective on cognitive processing and other effects.

In spite of the problems encountered with the first generation of nonselective muscarinic agonists, the use of M1 agonists remains a valid therapeutic strategy in $\mathrm{AD}$ patients. In fact, recent publications indicate that the M1 mAChR has a major role in modulating the pathology of $\mathrm{AD}$, and it is a relevant therapeutic target for other indications as well (e.g., dementia of Lewy body [DLB], Sjogren's syndrome, schizophrenia, and prion diseases). ${ }^{22,23,49,50}$ A significant amount of data was accumulated on compounds from the $\mathrm{AF}$ series (e.g., AF102B $\left[\left\{\right.\right.$ Cevimeline, EVOXAC $\left.{ }^{\mathrm{TM}}\right\}$ : prescribed in the United States of America and Japan for treatment of Sjogren's syndrome $^{49}$ ], AF150[S], and AF267B) (see reviews in references $\left.^{22,23}\right]$, and these partial M1 agonists are selected in this review to illustrate some of the relevant features of activating the M1 mAChR for AD treatment. This selection can be justified because these agonists are relatively selective for the $\mathrm{M} 1 \mathrm{mAChR}$, and through the activation of $\mathrm{M} 1 \mathrm{mAChR}$, they restore learning and memory impairments with a high safety margin in several animal models for $\mathrm{AD}$; they are neuroprotective, and they are potential disease modifiers through decreased $\mathrm{Ab}$ and tau pathologies. Whenever possible, these compounds from the $\mathrm{AF}$ series are compared with other putative M1 agonists or some other treatment strategies for $\mathrm{AD}$.

A number of other centrally active muscarinic agonists are reported, including: talsaclidine, ${ }^{51}$ YM796, ${ }^{52}$ CI$1017,{ }^{53}$ WAY-132983, ${ }^{54}$ CS- $932,{ }^{55}$ and LY-593093 ${ }^{56}$ [all claimed to be M1 functionally selective]. A few of the new agonists are defined as allosteric activators of the M1 mAChR. These include compounds such as: AC-42, AC$260584,{ }^{57}$ desmethylclozapine, ${ }^{57,58}$ and $77-$ LH-28-1 $1{ }^{59}$ The potential of M1 agonists and other compounds as diseasemodifying agents is discussed in the relevant sections as follows. 


\section{M2 muscarinic antagonists}

The rationale of designing M2 muscarinic antagonists for the treatment of $\mathrm{AD}$ is based on the hypothesis that central cholinergic activity can be induced not only by postsynaptic muscarinic agonists or AChE-Is, but also by facilitating $\mathrm{ACh}$ release. This can be achieved through inhibition of presynaptic inhibitory M2 mAChR. When $\mathrm{ACh}$ is released from the presynaptic terminals, it can activate the inhibitory presynaptic M2 mAChR leading to inhibition of further release of ACh. Studies have shown that blockade of $\mathrm{M} 2 \mathrm{mAChR}$ with muscarinic antagonists leads to increased levels of ACh in the brain. ${ }^{60}$ This enhanced release of $\mathrm{ACh}$, by activating postsynaptic M1 mAChR, can lead to improvement in cognitive processing, because M2 mAChR-knockout mice do not mediate cognition and memory, whereas M1 mAChRs are clearly involved in such processes. ${ }^{47,61,62}$ An additional advantage of M2 antagonists is that by elevating synaptic $\mathrm{ACh}$, these will also activate both postsynaptic mAChR, as well as nicotinic receptors. This would distinguish the M2 antagonists from M1 agonists, and serves to make this treatment approach more like AChE-Is at the level of the synapse. ${ }^{62}$

Some selective M2 antagonists, such as $\mathrm{SCH}-57790$ and SC-72788, ${ }^{63}$ restored memory impairments in animal models that mimic to some extent the cholinergic hypofunction in AD. These studies suggest that selective blockade of M2 mAChR may be a viable strategy for restoration of cognitive impairments.

Although some of the new M2 antagonists show a remarkable selectivity for the $\mathrm{M} 2 \mathrm{mAChR}$, and a relatively wide safety margin in behavioral studies, their potential benefit in AD still may be limited. First, peripheral $\mathrm{M} 2 \mathrm{mAChR}$, located in the heart, may cause bradychardia after stimulation with ACh. Therefore, as predicted, M2 antagonists cause tachycardia and because the cardiac and neuronal M2 mAChR are identical, it is not clear whether there is a separation between doses causing tachycardia versus those effective on cognition, respectively. In addition, the M2 $\mathrm{mAChR}$ are located on presynaptic cholinergic terminals projecting to the hippocampus and neocortex, and these are also the presynaptic cholinergic projections that degenerate in the course of $\mathrm{AD}$. In fact, $\mathrm{M} 2 \mathrm{mAChR}$ are progressively decreased in $\mathrm{AD} .{ }^{64}$ Therefore, it can be postulated that the effects of such M2 antagonists may be transient, as the approach is entirely dependent on enhanced release of presynaptic ACh, which is diminished as a result of a progressive presynaptic cholinergic hypofunction in AD. In this regard, the M2 antagonists may not offer a significant advantage versus the already prescribed AChE-Is in AD patients. ${ }^{65}$ Furthermore, while selective M1 agonists and some AChE-Is may have a potential as disease modifiers (see as follows), there is no such evidence yet for M2 antagonists. ${ }^{65}$

\section{Nicotinic agonists}

In $\mathrm{AD}$ there is a reduction in brain nicotinic receptor (nAChR) of $\alpha 3, \alpha 4 \beta 2$ and $\alpha 7$ subtypes. ${ }^{18,66,67}$ Preclinical studies in animal models and some pilot studies in AD showed that activation of nAChR can enhance cognitive impairments. ${ }^{66}$ The rationale in developing nicotinic treatments in $\mathrm{AD}$ rests on such findings,${ }^{66}$ as well as on the link of the nicotinic system with $A \beta .^{24,67} \mathrm{Nico}-$ tinic agonists, in particular, of $\alpha 4 \beta 2$ subtype, can enhance ACh release and also showed improved attention and memory in preclinical studies. ${ }^{66,67}$ The $\alpha 7$ nAChR is also at the center of major research and development efforts based on its role in learning and memory functions. ${ }^{66,67}$ In this context, the search for $\alpha 7 \mathrm{nAChR}$ agonists as a potential treatment for AD is being pursued by several research groups and drug companies.

For the past several years a large number of nicotinic compounds have been reported. A partial and incomplete list includes agonists with relative selectivity for $\alpha 4 \beta 2$ nAChR, such as: ABT- $418^{68}$, SIB-1553A ${ }^{69}$, RJR-2403 ${ }^{70}$, and $\alpha 7 \mathrm{nAChR}$ nicotinic agonists, such as: GTS-21 ${ }^{71}$, ARR1779, AR-R23465 $7^{72}$, and A-582941 ${ }^{73}$. Galantamine is the only compound that is Food and Drug Aministration-approved for $\mathrm{AD}$ treatment, and in addition to its AChEinhibitory profile, this compound is also a putative allosteric activator of $\alpha 4 \beta 2 \mathrm{nAChR}{ }^{74}$ The use of nicotinic agonists in $\mathrm{AD}$ patients is not without risk as these compounds can possess many of the adverse cholinergic toxicity observed with AChE-Is. Such agonists may have both beneficial and detrimental effects on some of AD hallmarks (see as follows), in addition to a potential addictive problem. This therapeutic strategy is considered in more detail as follows.

\section{HOW DO THE CHOLINERGIC TREATMENTS RELATE TO THE A $\beta$ AND TAU HYPOTHESES, RESPECTIVELY?}

There is compelling evidence that some select cholinergic treatments, and in particular M1 agonists, may provide in addition to improvement of cognitive deficits, also key therapies in $\mathrm{AD}$ against both $\mathrm{A} \beta$ and tau proteins pathologies as described as follows.

\section{In vitro studies}

A disruption of normal balance between $\alpha$-secretase on the one hand and $\beta$ - and $\gamma$-secretase on the other may lead to increased levels of $\mathrm{A} \beta$, presumed to be neurotoxic. ${ }^{2-7}$ In this regard, modulating the cholinergic pathway alters $A \beta$ accumulation and several studies were focused on activation of the mAChR subtypes and $A \beta$. Stimulation of M1 mAChRs can increase formation of $\alpha$-APPs, preventing the formation of $\mathrm{A} \beta .^{75-80}$ The mechanism attributed to these effects is M1 mAChRmediated activation of at least two transduction path- 
ways, protein kinase C (PKC)-, and mitogen-activated protein kinase (MAPK)-dependent pathways, that lead to activation of $\alpha$-secretase and elevation of $\alpha$-APPs secretion. $^{75,77}$

Stimulation of M3 mAChRs can also lead to enhanced $\alpha$-APPs elevation, in vitro. ${ }^{75}$ However, an M1 agonistfree M3 agonistic effects should be preferred because an M3 agonist can produce SE through activation of exocrine glands (e.g., gastrointestinal effects, salivation, lacrimation, and diaphoresis). ${ }^{23}$

Activation of either M2 mAChR or M4 mAChR is not effective in elevating $\alpha$-APPs, and stimulation of M2 mAChR may even have an inhibitory effect on $\alpha$-APPs release. ${ }^{74,80}$ In addition to other differences, this may separate the effects of AChE-Is versus direct-acting M1 agonists as AChE-Is due to inhibition of AChE elevate synaptic ACh levels that can activate M1-M5 mAChR subtypes, including the inhibitory M2 and M4 mAChR. ${ }^{8}$ Thus a possible elevation of $\alpha$-APPs via ACh-induced M1 mAChR activation may be masked (i.e., inhibited) by M $2 \mathrm{mAChR}$-activation. ${ }^{23}$ Indeed, mixed results were reported regarding the effects of AChE-Is on $\mathrm{A} \beta$ modulation. ${ }^{81}$ Thus $\alpha$-APPs were increased after treatment of cell cultures with some AChE-Is. ${ }^{82,83}$ This effect was attributed to indirect activation of post-synaptic M1 mAChR after synaptic elevation of ACh levels due to $\mathrm{AChE}$ inhibition. However, in some other studies AChE-Is did not induce an increase in $\alpha$-APPs in experimental designs where M1 mAChR activation lead to enhanced $\alpha$-APPs secretion. ${ }^{75}$ Given the apparent contradictory results with AChE-Is on $\alpha$-APPs levels, it was suggested that different AChE-Is may differ in their actions on APP metabolism. ${ }^{81,84}$

Nicotinic receptor activation may also stimulate nonamyloidogenic cleavage of $\beta$ APP to elevate $\alpha$-APPs. ${ }^{85}$

One method for decreasing $A \beta$ production could be via modulation of APP synthesis. This strategy was pursued with phenserine, an AChE-Is. ${ }^{86}$ Notably, in addition to blocking $\mathrm{AChE}$, phenserine in neuronal cells reduces levels of $\mathrm{A} \beta$, APP and $\alpha$-APPs, which has significant neuroprotective and neurotrophic functions. One hypothesis to explain the findings attributed the effects of phenserine to inhibition of APP translation using a pathway dependent on the interleukin-responsive element that is a translational regulation motif, identified in the 5, untranslated region of APP mRNA. ${ }^{86}$

Hyperphosphorylated tau, the other hallmark of AD, can be modulated by several treatments, including the cholinergic drugs as described as follows. Relevant to the scope of this review is the regulation of glycogen synthase kinase- $3 \beta$ (GSK-3 $\beta$ ). ${ }^{87-90}$ GSK-3 $\beta$ is a physiological kinase for tau and is a candidate protein kinase involved in the hyperphosphorylation of tau present in paired helical filaments-tau of NFT in AD. Notably, GSK-3 $\beta$ has been postulated to mediate AD tau hyper- phosphorylation, $\mathrm{A} \beta$-induced neurotoxicity, and presenilin-1 mutation pathogenic effects. ${ }^{87-90}$ Increased levels of GSK- $3 \beta$ have been found in $\mathrm{AD}$, and in particular neuritic plaques, and GSK- $3 \beta$ has been associated with NFT in AD brain. ${ }^{91}$ In this context, it is of special interest that activation of M1 mAChR decreases tau phosphorylation as shown in vitro and in vivo. ${ }^{26,91-94}$ Activation of M1 mAChR decreases tau hyperphosphorylation via activation of PKC and inhibition of GSK-3 $\beta .^{26,92}$

Although less studied than the impact of AChE-Is and nicotinic agonists on APP processing, a few in vitro experiments have indicated that these drugs can increase tau immunoreactivity and alter its phosphorylation state (e.g., increased both tau phosphorylated and dephosphorylated levels), probably via nAChR. ${ }^{95}$ In fact, activation of $\alpha 7 \mathrm{nAChR}$ may be involved in $\mathrm{A} \beta$-induced tau phosphorylation. ${ }^{96}$ Thus, it is possible that nAChR modulation, under conditions of elevated $\mathrm{A} \beta$, may contribute to tau pathology in $\mathrm{AD} .{ }^{67}$ Therefore, while $\alpha 7 \mathrm{nAChR}$ agonists appear to have a major role in cognitive processing and nicotinic agonists, in particular $\alpha 7$ selective, protecting neurons from $\mathrm{A} \beta$-induced neurotoxicity, this therapeutic strategy may also enhance tau hyperphosphorylation and mimic the toxic actions of $\mathrm{A} \beta$. Notably, $\alpha 7$ $\mathrm{nAChR}$ antagonists, rather than agonists were proposed as a more rational therapeutic strategy in $\mathrm{AD} .{ }^{97}$

$\mathrm{A} \beta$ is neurotoxic and this is evidenced, inter alia, at several levels as evidenced by detrimental effects on $\mathrm{ACh}$ regulation and release, production of reactive oxidative species, induction of oxidative stress, inflammation, activation of GSK- $3 \beta$ and elevation of tau hyperphosphorylation, impairment of cell viability, induction of cell death, and apoptosis. ${ }^{24,98}$ In this context, exposure of cortical slices to fibrillar $A \beta$ induced a marked increase in the activation of PKC and $\mathrm{Ca}^{2+} /$ calmodulindependent kinase II (CaMKII), which are two enzymes critically involved in a variety of cellular functions. Activation of M1 mAChR, but not nicotinic receptors, significantly inhibited $A \beta$-induced activation of PKC and CaMKII. Activation of M1 mAChR inhibits $A \beta$ signaling by enhancing the counteracting GABAergic inhibitory transmission. ${ }^{99}$ Therefore, M1 muscarinic reversal of the $\mathrm{A} \beta$-induced biochemical and physiological changes provides a potential mechanism for the treatment of AD with M1 agonists. From a different perspective, M1 muscarinic agonists via M1 mAChR activation can inhibit $\mathrm{A} \beta$-induced toxicity on cell cultures. ${ }^{100,101}$ Thus, AF267B via activation of M1 mAChR protects hippocampal neurons from $\mathrm{A} \beta$-toxicity, and apoptosis and this effect is achieved by the activation of the Wnt signaling, since M1 mAChR activates PKC, inhibits GSK-3 $\beta$ activity, stabilizes cytoplasmic and nuclear $\beta$-catenin, as well as induces the Wnt target genes expression of engrailed and cyclin-Dl, reverting the switch off of the Wnt pathway caused by $\mathrm{A} \beta$-toxicity. ${ }^{101}$ These 
results point to a cross-talk between the M1 mAChR signalling and the Wnt components and add a further value to use M1 agonists in AD therapy. ${ }^{101}$ Notably, Wnt signaling appears to be compromised in AD. ${ }^{102,103}$ Stimulation of nicotinic receptors ${ }^{104,105}$ and some AChE-Is ${ }^{106}$ also prevent $\mathrm{A} \beta$-induced neuronal death, albeit the mechanism underlying these effects may differ.

\section{In vivo studies}

Studies in vivo support the relation between the cholinergic system and $\mathrm{A} \beta$ metabolism. Thus, in rabbits, where the sequence of $A \beta 42$ is similar to humans, the three M1 selective agonists AF102B, AF267B and $\mathrm{AF} 150(\mathrm{~S})$ decreased $\mathrm{A} \beta 40$, whereas $\mathrm{AF} 267 \mathrm{~B}$ and $\mathrm{AF} 150(\mathrm{~S})$ also reduced levels of $\mathrm{A} \beta 42$ in the CSF without changing $\alpha$-APPs. ${ }^{107}$ Lesioning the cholinergic nucleus basalis magnocellularis in rabbits with a selective cholinergic immunotoxin results in cortical cholinergic deafferentation and cortical $\mathrm{A} \beta$ deposition. ${ }^{108}$ The $\mathrm{A} \beta$ deposits are primarily vascular, with occasional perivascular plaques. ${ }^{108}$ The specificity of this change for cholinergic processes has been demonstrated by the reduction of lesion-induced $\mathrm{A} \beta$ deposition in the cortex, and CSF by chronic cholinergic therapy with the M1 agonist AF267B and the AChE-Is physostigmine, and by showing that lesioning of the noradrenergic locus ceruleus does not cause $\mathrm{A} \beta$ deposition. ${ }^{108}$

In triple transgenic mice $(3 \times \mathrm{Tg}-\mathrm{AD})$ that recapitulate cognitive impairments, $A \beta$ and tau pathologies ${ }^{109}$ prolonged intraperitoneal treatment with low doses of AF267B- improved significantly hippocampal-dependent memory impairments; caused a decrease in $A \beta 42$ in both soluble and insoluble fraction in treated mice compared with untreated mice, and decreased $A \beta 42$ both intracellular, extracellular, and tau hyperphosphorylation and pathological tau (in cortex and hippocampus, but not in amygdala). ${ }^{26}$ AF267B rescued cognitive deficits and decreased $A \beta 42$ and tau pathologies in the cortex and hippocampus, via M1mAChR-activation of ADAM17/ TACE, and decreased BACE1 and GSK- $3 \beta$ steady state levels and GSK- $3 \beta$ activity, extending findings from in vitro studies. The M1 agonist AF267B is the first reported low molecular weight CNS-penetrable compound that comprehensively targets these hallmarks, and it may become a major therapy in AD. Earlier studies also showed that activation of M1 mAChR decreases tau hyperphosphorylation in additional in vivo models (in apolipoprotein E-deficient mice, ${ }^{93}$ and in aged microcebes $^{94}$ [a natural model the recapitulates both AD pathology and cognitive impairments, reviewed in $\left.{ }^{110}\right]$ ).

Other types of cholinergic therapies have also been used in an attempt to decrease or prevent $\mathrm{A} \beta$ deposition, with mixed results. Nicotine treatment resulted in an $80 \%$ decrease in plaque load and 50 to $60 \%$ reductions in cortical A $\beta$ concentrations in the Tg2575/PS1-A246E mice, ${ }^{111}$ but not in $3 \times \mathrm{Tg}$-AD mice (see as follows). ${ }^{112}$ The AChE-Is metrifonate failed to reduce $\mathrm{A} \beta$ deposition in double transgenic (Tg) (Tg2575/PS1-A246E) mice. ${ }^{113}$ In the AD11 Tg mouse the AChE-Is donepezil and ganstigmine restored the cholinergic and behavioral deficits, but did not reduce $\mathrm{A} \beta$ levels and tau hyperphosphorylation. ${ }^{114}$ It is important to mention, however, that chronic donepezil treatment improved spatial accuracy in APP23 mice so as to reach the same level of performance as wild-type control animals on this complex visual-spatial learning task. This study reported a disease-modifying efficacy of donepezil at the level of cognitive performance in Tg mice modeling AD. ${ }^{15}$ The $3 \times$ Tg-AD model offers the possibility of answering fundamental questions in AD pathology and some therapeutic strategies, in addition to AF267B as tested so far in this model. Whether AF267B is more beneficial than AChE-Is prescribed in $\mathrm{AD}$ can not be addressed properly, because there are no publications on AChE-Is in the 3xTg-AD mice. Notably, unlike the beneficial effects observed for the M1 agonist AF267B, ${ }^{26}$ chronic nicotine treatment, albeit not in comparative study, is causing an increase in phosphorylated and pathological tau-activating p38-MAP kinases and had no effect on $\mathrm{A} \beta$ in the same $3 \times \mathrm{xTg}-\mathrm{AD}$ mice model. ${ }^{112}$ Notably, $\alpha 7$ nAChR gene delivery into mouse hippocampal neurons leads to functional receptor expression, improved spatial memory-related performance, and tau hyperphosphorylation. ${ }^{116}$ Because M1 muscarinic agonists promote tau dephosphorylation, such compounds could reduce in principle tangle formation. This may separate M1 agonists from nicotinic agents and perhaps AChE-Is as well.

\section{SOME RELEVANT CLINICAL STUDIES ON AD MODIFICATION}

A few studies have addressed the question whether cholinergic treatments can have an impact on disease modification. Thus, chronic treatment with the M1 agonists, $\mathrm{AF} 102 \mathrm{~B}^{117}$ and talsaclidine ${ }^{118}$ resulted in a modest, but significant, decrease of CSF $A \beta$ in $\mathrm{AD}$ patients, whereas the AChE-Is physostigmine, ${ }^{117}$ galantamine, donepezil, ${ }^{119}$ and hydroxychloroquine (an anti-inflammatory drug) $)^{117}$ were ineffective. The clinical significance of these findings with M1 agonists remains to be established, yet it is possible that the observed effect of these agonists reflect the outcome of a therapy designed to alter APP processing. Notably the preclinical data (e.g., normal and lesioned rabbits, respectively) ${ }^{107,108}$ showed that a decrease in the CSF A $\beta$ induced by M1 agonists is paralleled by a cortical decrease in soluble $\mathrm{A} \beta$ levels.

Although the tested AChE-Is did not appear to affect CSF A $\beta$ levels in AD patients, the impact of cholinesterase inhibitor treatment on brain pathology after au- 
topsy was examined in treated patients with dementia with Lewy bodies with matched, untreated patients for cortical $\mathrm{A} \beta$ and tau pathologies. Cholinesterase inhibitor-treated patients with DLB had significantly less parenchymal $\mathrm{A} \beta$ deposition, but no significant effect on tau pathologies, which is relevant to disease management and treatment of dementia patients using cholinesterase inhibitors. The clinical significance of these important findings remains yet to be clarified. ${ }^{120}$

In a clinical study recently published, ${ }^{35}$ phenserine caused statistically significant effects in patients with mild $\mathrm{AD}$ on a composite neuropsychological test score compared with the placebo and donepezil at 3 and 6 months, respectively. Values of regional cerebral metabolic rate for glucose (rCMRglc) were significantly increased in several cortical regions after 3 months of phenserine treatment, compared with baseline, and correlated positively with cognitive function and CSF A $\beta 40$. Cortical Pittsburgh Compound B retention correlated negatively with $\mathrm{CSF} A \beta 40$ levels and the ratio $\mathrm{A} \beta / \beta$-secretase-cleaved APP. In CSF, A $\beta 40$ correlated positively with the attention domain of cognition. The study demonstrated also the value of the positron emission tomographic scan technique in evaluating drugs for $\mathrm{AD}$ treatment.

Remarkably, while $\mathrm{M} 1$ agonists can decrease brain $\mathrm{A} \beta$ and tau phosphorylation in animal models a relatively selective antagonist to $\mathrm{M} 1 \mathrm{mAChR}$, dicyclomine is exacerbating the AD-type pathologies in the 3xTg-AD mice. ${ }^{26}$ Furthermore, an increased AD-type pathology (plaques and tangles) in Parkinson's disease is associated with chronic treatment with anti-muscarinc drugs (some relatively selective M1 antagonists). ${ }^{121}$ Thus, it would appear that the M1 mAChR is strongly linked with $\mathrm{A} \beta$ processing so that chronic activation or inhibition of this receptor subtype can decrease or increase the brain $\mathrm{A} \beta$ burden, respectively.

\section{CONCLUSIONS AND FUTURE PERSPECTIVES}

In spite of a few publications, ${ }^{35,120}$ AChE-Is, the mainstay of the current treatments in $\mathrm{AD}$, are still regarded as symptomatic treatments, and such drugs may lack a beneficial effect in preventing disease progression based on: 1) clinical long term experience and 2) preclinical findings, inter alia, regarding nicotinic effects that may in fact increase tau phosphorylation and M2 muscarinic effects that may prevent $\alpha$-APPs release. This may be attributed to elevated synaptic ACh levels after $\mathrm{AChE}$ inhibition that activate in a promiscuous way all muscarinic and nicotinic receptors subtype, whether needed or not. The use of nAChR and mAChR agonists may represent another means for activating cholinergic receptors in the $\mathrm{AD}$ brain. In this regard, activation of nAChRs by chronic nicotine exposure exacerbates tau pathology in the $3 x \mathrm{Tg}$-AD mice. ${ }^{112}$ It remains to be seen whether more selective nicotinic agonists will be devoid of such detrimental effects at doses that have a beneficial effect on cognition. In contrast, the results in 3xTg-AD mice show the remarkable therapeutic potential of AF267B in attenuating the major hallmark neuropathological lesions relevant to $\mathrm{AD}$ and in restoring cognitive function. ${ }^{26}$

Future therapies will have to provide a superior profile versus the available AChE-Is prescribed for treatment of AD. The ideal therapy should be beneficial both as a symptomatic as well as disease modifier. A disease modifier must have a significant effect also on the major clinical manifestations of $\mathrm{AD}$, cognitive, and memory dysfunctions. $^{2,12,122}$ In this context, it is noteworthy that some M1 agonists such as AF267B can be beneficial on the three major hallmarks of $\mathrm{AD}$ : 1) $\mathrm{A} \beta, 2$ ) tau hyperphosphorylation, and 3) cognitive dysfunctions via $\mathrm{PKC}$ activation. Taken together, these new findings may modify the over-simplistic cholinergic hypothesis in $\mathrm{AD}$ that was limited to a symptomatic treatment and ignored the added potential of M1 agonists as disease-modifying agents. However, only well-designed clinical trials will show whether the new generation of M1 agonists, such as AF267B (tested in phase I studies ${ }^{123}$ ) can become effective treatments in AD.

\section{REFERENCES}

1. Blennow K, deLeon MJ, Zetterberg H. Alzheimer's disease. Lancet. 2006;368:387-403.

2. Cuello CA. Overview of the Alzheimer's disease pathology and potential therapeutic targets. In: Pharmacological mechanisms in Alzheimer's therapeutic. Cuello CA, ed. New York: Springer, 2008, $1-27$.

3. Wolfe MS, Therapeutic strategies for Alzheimer's disease. Nat Rev Drug Discov 2002;1:859-866.

4. Hooper NM, Turner AJ. The search for alpha-secretase and its potential as a therapeutic approach to Alzheimer s disease. Current Med Chem 2002;9:1107-1119.

5. Racchi M, Govoni S. The pharmacology of amyloid precursor protein processing. Exp Gerontol 2003;38:145-157.

6. Gandy SE, Petanceska S. Regulation of Alzheimer's $\beta$-amyloid precursor trafficking and metabolism. Biochim Biophys Acta 2000;1502:44-52.

7. Palmer AM. Pharmacotherapy for Alzheimer's disease: progress and prospects. Trends Pharmacol Sci 2002;23:426-433.

8. Hardy JA, Higgins GA. Alzheimer's disease: the amyloid cascade hypothesis. Science 1992;256:184-185.

9. Tanzi RE, Bertram L. Twenty years of the Alzheimer's disease amyloid hypothesis: a genetic perspective. Cell 2005;120:545555 .

10. Robinson SR, Bishop GM. Abeta as a bioflocculant: implications for the amyloid hypothesis of Alzheimer's disease. Neurobiol Aging 2002;23:1051-1072.

11. Rottkamp CA, Atwood CS, Joseph JA. The state versus amyloidbeta: the trial of the most wanted criminal in Alzheimer disease. Peptides 2002;23:1333-1341.

12. Salloway S, Mintzer J, Weiner MF, Cummings JL. Diseasemodifying therapies in Alzheimer's disease. Alzheimers Dement 2008;4:65-79.

13. Birks J. 2006. Cholinesterase inhibitors for Alzheimer's disease. Cochrane Database Syst Rev CD005593. 
14. Ringman JM, Cummings JL. Current and emerging pharmacological treatment options for dementia. Behav Neurol 2006;17:516.

15. Bartus RT. On neurodegenerative diseases, models, and treatment strategies: lessons learned and lessons forgotten a generation following the cholinergic hypothesis. Exp Neurol 2000;163:495529.

16. Geula C, Nagykery N, Nicholas A, Wu CK. Cholinergic neuronal and axonal abnormalities are present early in aging and in Alzheimer disease. J Neuropathol Exp Neurol 2008;67:309_ 318 .

17. Ladner CJ, Lee JM. Pharmacological drug treatment of Alzheimer disease: the cholinergic system revisited. J Neuropathol Exptl Neurol 1998;57:719-731.

18. Perry EK, Court J, Goodchild R, et al. Clinical neurochemistry: developments in dementia research based on brain bank material. J Neural Transm 1998;105:915-933.

19. Iqbal K, Alonso A del C, Gondal JA, et al. Mechanism of neurofibrillary degeneration and pharmacologic therapeutic approach. J Neural Transm 2000;59:213-222.

20. Seabrook GR, Ray WJ, Shearman M, Hutton M. Beyond amyloid: the next generation of Alzheimer's disease therapeutics. Mol Interv 2007;7:261-270.

21. Mudher A, Lovestone S. Alzheimer's disease-do tauists and baptists finally shake hands? Trends Neurosci 2002;25:22-26.

22. Fisher A. Therapeutic strategies in Alzheimer's disease: M1 muscarinic agonists. Jap J Pharmacol 2000;84:101-112.

23. Fisher A. Muscarinic agonists and antagonists-some therapeutic applications. In: Giacobini E and Pepeu G, eds. The Brain Cholinergic System in Health and Disease. Boca Raton (FL): Informa Healthcare, Taylor \& Francis Publishers 2005;169-180.

24. Auld DS, Kornecook TJ, Bastianetto S, Quirion R. Alzheimer's disease and the basal forebrain cholinergic system: relations to beta-amyloid peptides, cognition, and treatment strategies. Prog Neurobiol 2002;68:209-245.

25. Rubio A, Perez M, Avila J. Acetylcholine receptors and tau phosphorylation. Curr Mol Med 2006;6:423-428.

26. Caccamo A, Oddo S, Billings LM, Martinez-Coria H, Fisher A, LaFerla FM. M1 receptors play a central role in modulating AD-like pathology in transgenic mice. Neuron 2006;49:671-682.

27. Standridge JB. Pharmacotherapeutic approaches to the treatment of Alzheimer's disease. Curr Ther 2004;26:615-630.

28. Giacobini E. Do cholinesterase inhibitors have disease-modifying effects in Alzheimer's disease? CNS Drugs 2001;15:85-91.

29. Gauthier S. Cholinergic adverse effects of cholinesterase inhibitors in Alzheimer's disease: epidemiology and management. Drugs \& Aging 2001;18:853-862.

30. Schneider LS. Treatment of Alzheimer's disease with cholinesterase inhibitors. Clin Geriat Med 2001;17:337-358.

31. Courtney C, Farrell D, Gray R, et al. Long-term donepezil treatment in 565 patients with Alzheimer's disease (AD2000): randomised double-blind trial. Lancet 2004;363(9427):2105-2115.

32. Lilienfeld S. Galantamine-a novel cholinergic drug with a unique dual mode of action for the treatment of patients with Alzheimer's disease. CNS Drug Rev 2002;8:159-176.

33. Raschetti R, Albanese E, Vanacore N, Maggini M. Cholinesterase inhibitors in mild cognitive impairment: a systematic review of randomised trials. PLoS Med 2007;4(11):e338.

34. Lahiri DK, Farlow MR, Greig NH, et al. Current drug targets for Alzheimer's disease treatment. Drug Develop Res 2002;56:267281.

35. Kadir A, Andreasen N, Almkvist O, et al. Effect of phenserine treatment on brain functional activity and amyloid in Alzheimer's disease. Ann Neurol 2008; [Epub ahead of print].

36. Trabace L, Cassano T, Loverre A, et al. CHF2819: pharmacological profile of a novel acetylcholinesterase inhibitor. CNS Drug Reviews 2002;8:53-69.

37. Ishihara Y, Goto G, Miyamoto M. Central selective acetylcholinesterase inhibitor with neurotrophic activity: structure-activity relationships of TAK-147 and related compounds. Current Med Chem 2000;7:341-354.

38. Weinstock M, Luques L, Bejar C, Shoham S.Ladostigil. A novel multifunctional drug for the treatment of dementia co-morbid with depression. J Neural Transm Suppl 2006;70:443-446.

39. Bai DL, Tang XC, He XC, Huperzine A. A potential therapeutic agent for treatment of Alzheimer's disease. CNS Drug Rev 2000; 7:355-374.

40. García-Palomero E, Muñoz P, Usan P, et al. Potent beta-amyloid modulators. Neurodegener Dis 2008;5:153-156.

41. Bolognesi ML, Banzi R, Bartolini M, et al. Novel class of quinone-bearing polyamines as multi-target-directed ligands to combat Alzheimer's disease. J Med Chem 2007;50:4882-4897.

42. Giacobini E. Selective inhibitors of butyrylcholinesterase-a valid alternative for therapy of Alzheimer's disease? Drugs Aging 2001;18: 891-898.

43. Levey AI. Muscarinic acetylcholine receptor expression in memory circuits: implications for treatment of Alzheimer disease. Proc Natl Acad Sci USA 1996;93:13541-13546.

44. Volpicelli LA, Levey AI. Muscarinic acetylcholine receptor subtypes in the cerebral cortex and hippocampus. Prog Brain Res 2004;145:59-66.

45. Svensson AL, Alafuzof I, Nordberg A. Characterization of muscarinic receptor subtypes in Alzheimer and control brain cortices by selective muscarinic antagonists. Brain Res 1992;596:142148.

46. Mulugeta E, Karlsson E, Islam A, et al. Loss of muscarinic M(4) receptors in hippocampus of Alzheimer patients. Brain Res 2003; 960:259-262.

47. Anagnostaras SG, Murphy GG, Hamilton SE, et al. Selective cognitive dysfunction in acetylcholine M1 muscarinic receptor mutant mice. Nature Neurosci 2003;6:51-58.

48. Beach TG. Muscarinic agonists as preventative therapy for Alzheimer's disease. Curr Opin Invest Drugs 2002;3:1633-1636.

49. Fox R, Kontinnen Y, Fisher A. Use of muscarinic agonists in the treatment of Sjogren's syndrome. Clin Immunol 2002;101:249263.

50. Alfa Cisse M, Sunyach C, Slack BE, Fisher A, Vincent B and Checler F. M1 and M3 muscarinic receptors control physiological processing of cellular prion by modulating ADAM17 phosphorylation and activity. J Neurosci 2007;27:4083-4092.

51. Wienrich M, Ceci A, Ensinger HA, et al. Talsaclidine (WAL 2014 FU): a muscarinic M1 receptor agonist for the treatment of Alzheimer's disease. Drug Develop Res 2002;56:321-334.

52. Wanibuchi F, Konishi T, Harada M, et al. Pharmacological studies on novel muscarinic agonists, 1-oxa-8-azaspiro[4.5]decane derivatives YM796 and YM954. Eur J Pharmacol 1990;187:479486.

53. Tecle H, Schwarz RD, et al. CI-1017, a functionally M1-selective muscarinic agonist: design, synthesis, and preclinical pharmacology. Pharm Acta Helv 2000;74:141-148.

54. Bartolomeo AC, Morris H, Buccafusco JJ, et al. The preclinical pharmacological profile of WAY-132983, a potent M1 preferring agonist. J Pharmacol Exp Ther 2000;292:584-596.

55. Iwata N, Kozuka M, Hara T, et al. Activation of cerebral function by CS-932, a functionally selective M1 partial agonist: neurochemical characterization and pharmacological studies. Jpn J Pharmacol 2000;84:266-280.

56. Hitchcock S, Allen J, Baker A, et al. Discovery of a novel class of selective M1 agonists suitable for clinical development. Abstracts of papers, 225th ACS National Meeting, New Orleans, LA, March 23-27, 2003; Stanley PK. Development of a scalable process for the synthesis of LY593093, www.albmolecular.com/ chemlinks/reviews/vol08/no21/v08n21.pdf.

57. Spalding TA, Ma JN, Ott TR, et al. Structural requirements of transmembrane domain 3 for activation by the $\mathrm{m} 1$ muscarinic receptor agonists AC-42, AC-260584, clozapine, and N-desmethylclozapine: evidence for three distinct modes of receptor activation. Mol Pharmacol 2006;70:1974-1983.

58. Sur C, Mallorga PJ, Wittmann M, et al. N-desmethylclozapine, an allosteric agonist at muscarinic 1 receptor, potentiates N-methylD-aspartate receptor activity. Proc Natl Acad Sci U S A 2003; 100:13674-13679.

59. May LT, Avlani VA, Langmead CJ, et al. Structure-function studies of allosteric agonism at M2 muscarinic acetylcholine re- 
ceptors. Mol Pharmacol 2007;72:463-476; Langmead.CJ. www.monash.edu.au/cmo/molecular/Program.pdf.

60. Feuerstein TJ, Lehman J, Suerman W, et al. The autoinhibitory feedback control of acetylcholine release in human neocortex tisue. Brain Res 1992;572:64-71.

61. Wess J, Eglen RM, Gautam D. Muscarinic acetylcholine receptors: mutant mice provide new insights for drug development. Nat Rev Drug Discov 2007;6:721-733.

62. Clader JW, Wang Y. Muscarinic receptor agonists and antagonists in the treatment of Alzheimer's disease. Curr Pharm Des 2005;11:3353-3361.

63. Boyle CD, Lachowicz JE. Orally active and selective benzylidene ketal M2 muscarinic receptor antagonists for the treatment of Alzheimer's disease. Drug Dev Res 2002;56:310-320.

64. Mash DC, Flynn DD, Potter LT. Loss of M2 muscarine receptors in cerebral cortex in Alzheimer's disease and experimental cholinergic denervation. Science 1985;228:1115-1117.

65. Sheardown MJ. Muscarinic M1 receptor agonists and M2 receptor antagonists as therapeutic targets in Alzheimer's disease. Expert Opin Ther Patents 2002;12:863-870.

66. Woodruff-Pak DS. Preclinical experiments on cognition enhancement in Alzheimer's disease: Drugs affecting nicotinic acetylcholine receptors. Drug Dev Res 2002;56:335-346.

67. Dineley KT. Beta-amyloid peptide-nicotinic acetylcholine receptor interaction: the two faces of health and disease. Front Biosci 2007;12:5030-5038.

68. Arneric SP, Holladay MW, Sullivan JP. Cholinergic channel modulators as a novel therapeutic strategy for Alzheimer's disease. Exp Opin Invest Drugs 1996;5;79-100.

69. Bontempi B, Whelan KT, Risbrough VB, et al. SIB-1553A, (+/)-4-[[2-(1-methyl-2-pyrrolidinyl)ethyl]thio] phenol hydrochloride, a subtype-selective ligand for nicotinic acetylcholine receptors with putative cognitive-enhancing properties: effects on working and reference memory performances in aged rodents and nonhuman primates. J Pharmacol Exp Ther 2001;299:297-306.

70. Bencherif M, Byrd G, Caldwell WS, et al. Pharmacological characterization of RJR-2403: a nicotinic agonist with potential therapeutic benefit in the treatment of Alzheimer's disease. CNS Drug Rev 1997;3:325-345.

71. Kem WR. The brain alpha7 nicotinic receptor may be an important therapeutic target for the treatment of Alzheimer's disease: studies with DMXBA (GTS-21). Behav Brain Res 2000;113: $169-181$.

72. Daly JW. Nicotinic agonists, antagonists, and modulators from natural sources Cell Molec Neurobiol 2005:25:512-552.

73. Bitner RS, Bunnelle WH, Anderson DJ, et al. Broad-spectrum efficacy across cognitive domains by alpha7 nicotinic acetylcholine receptor agonism correlates with activation of ERK1/2 and CREB phosphorylation pathways. J Neurosci 2007;27:1057810587.

74. Coyle J, Kershaw P. Galantamine, a cholinesterase inhibitor that allostericallty modulates nicotinic receptors: effects on the course of Alzheimer's disease. Biolog Psych 2002;49:289-299.

75. Nitsch RM, Slack BE, Wurtman RJ, Growdon JH. Release of Alzheimer amyloid precursor derivatives stimulated by activation of muscarinic acetylcholine receptors. Science 1992;58:304-307.

76. Wolf BA, Wertkin AM, Jolly YC, et al. Muscarinic regulation of Alzheimer's disease amyloid precursor protein secretion and amyloid beta-protein production in human neuronal NT2N cells. J Biol Chem 1995;270:4916-4922.

77. Haring R, Fisher A, Marciano D, et al. Mitogen-activated protein kinase-dependent and protein kinase $\mathrm{C}$-dependent pathways link the M1 muscarinic receptor to amyloid precursor protein secretion. J Neurochem 1998;71:2094-2103.

78. Pittel Z, Heldman E, Barg J, Haring R, Fisher A. Muscarinic control of amyloid precursor protein secretion in rat cerebral cortex and cerebellum. Brain Res 1996;742:299-304.

79. Müller DM, Mendla K, Farber SA, Nitsch RM. Muscarinic M1 receptor agonists increase the secretion of the amyloid precursor protein ectodomain. Life Sci 1997;60:985-991.

80. Davis AA, Fang G, Huang X, Wess J, Levey AI. Muscarinic receptor regulation of amyloid precursor protein processing in primary neuronal cultures. Neurodegener Dis 2007;4(suppl 1):97.
81. Racchi M, Mazzucchelli M, Porrello E, Lanni C, Govoni S. Acetylcholinesterase inhibitors: novel activities of old molecules. Pharmacol Res 2004;50:441-451.

82. Mori F, Lai CC, Fusi F, Giacobini E. Cholinesterase inhibitors increase secretion of APPs in rat brain cortex. Neuroreport 1995; 6:633-636.

83. Pakaski M, Rakonczay Z, Kasa P. Reversible and irreversible acetylcholinesterase inhibitors cause changes in neuronal amyloid precursor protein processing and protein kinase $\mathrm{C}$ level in vitro. Neurochem Int 2001;38:219-226.

84. Lahiri DK, Farlow MR. Differential effect of tacrine and physostigmine on the secretion of the beta-amyloid precursor protein in cell lines. J Mol Neurosci 1996;7:41-49.

85. Kim SH, Kim YK, Jeong SJ, et al. Enhanced release of secreted form of Alzheimer's amyloid precursor protein from PC12 cells by nicotine. Mol Pharmacol 1997;52:430-436.

86. Lahiri DK, Farlow MR, Hintz N, et al. Cholinesterase inhibitors, $\beta$-amyloid precursor protein and amyloid $\beta$-peptides in Alzheimer's disease. Acta Neurol Scand 2000;176(suppl):60-67.

87. Grimes CA, Jope RS. The multifaceted roles of glycogen synthase kinase-3 $\beta$ in cellular signaling. Prog Neurobiol 2001;65: 391-426.

88. De Sarno P, Bijur GN, Zmijewska AA, Li X, Jope RS. In vivo regulation of GSK3 phosphorylation by cholinergic and NMDA receptors. Neurobiol Aging 2006;27:413-422.

89. Balaram Y, Lymaye AR, Levey AI, Srinivasan S. GSK- $3 \beta$ and Alzheimer's disease: pathological and therapeutic significance. Cell Mol Life Sci 2006;63:1226-1235.

90. Leroy K, Yilmaz Z, Brion JP. Increased level of active GSK3beta in Alzheimer's disease and accumulation in argyrophilic grains and in neurones at different stages of neurofibrillary degeneration. Neuropathol Appl Neurobiol 2007;33:43-55.

91. Sadot E, Gurwitz D, Barg J, Behar R, Ginzburg I, Fisher A. Activation of M1-muscarinic acetylcholine receptor regulates tau phosphorylation in transfected PC12 cells. J Neurochem 1996; 66:877-880.

92. Forlenza OV, Spink JM, Dayanandan R, Anderton BH, Olesen OF, Lovestone S. Muscarinic agonists reduce $\tau$ phosphorylation in non-neuronal cells via GSK-3 $\beta$ inhibition and in neurons. J Neural Transm 2000;107:1201-1212.

93. Genis I, Fisher A, Michaelson DM. Site-specific dephosphorylation of tau in apolipoprotein E-deficient and control mice by M1 muscarinic agonist treatment. J Neurochem 1999;12:206-213.

94. Fisher A, Kealler E, Bons N. Cognitive and behavioral improvements in the aged primate Microcebus murinus following one year treatment with the M1 muscarinic agonist, AF150(S). World Conference on AD: Washington DC, July 9-13, 2000.

95. Hellstrom-Lindahl E, Moore H, Nordberg A. Increased levels of $\tau$ protein in SH-SY5Y cells after treatment with cholinesterase inhibitors and nicotinic agonists. J Neurochem 2000;74:777-784.

96. Wang H-Y, Li W, Benedetti NJ, Lee DHS. Alpha 7 nicotinic acetylcholine receptors mediate beta-amyloid peptide-induced tau protein phosphorylation. J Biol Chem 2003;278:31547-31553.

97. Dineley K T, Westerman M, Bui D, et al. Beta-amyloid activates the mitogen activated protein kinase cascade via hippocampal alpha7 nicotinic acetylcholine receptors: in vitro and in vivo mechanisms related to Alzheimer's disease. J Neurosci 2001; 4125-4133.

98. Mattson MP. Central role of oxyradicals in the mechanism of amyloid $\beta$-peptide cytotoxicity. Alzheimer's Dis Rev 1997;2:114.

99. Gu Z, Zhong P, Yan Z. Activation of muscarinic receptors inhibits beta-amyloid peptide-induced signaling in cortical slices. J Biol Chem 2003;278:17546-17556.

100. Fisher A, Brandeis R, Bar-Ner N, et al. AF150(S) and AF267B: M1 muscarinic agonists as innovative therapies for Alzheimer's disease. J Mol Neurosci 2002;19:145-153.

101. Farias GG, Godoy JA, Hernandez F, Avila J, Fisher A, Inestrosa NC. M1 muscarinic receptor activation protects neurons from beta-amyloid toxicity. A role for Wnt signaling pathway. Neurobiol Dis 2004;17:337-348.

102. De Ferrari GV, Inestrosa NC. Wnt signaling function in Alzheimer's disease. Brain Res Rev 2000;33:1-12. 
103. Mudher A, Lovestone S. Alzheimer's disease-do tauists and baptists finally shake hands? Trends Neurosci 2002;25:22-26.

104. Kihara T, Shimohama S, Sawada H, et al. Nicotinic receptor stimulation protects neurons against $\beta$-amyloid toxicity. Ann Neurol 1997;42:159-163.

105. Kihara T, Shimohama S, Urushitani M, et al. Stimulation of $\alpha 4 \beta 2$ nicotinic acetylcholine receptors inhibits $\beta$-amyloid toxicity. Brain Res 1998;792:331-334.

106. Svensson AL, Nordberg A. Tacrine and donepezil attenuate the neurotoxic effect of $\mathrm{A} \beta(25-35)$ in rat PC12 cells. Neuroreport 1998;9:1519-1522.

107. Beach TG, Walker DG, Potter PE, Sue LI, Fisher A. Reduction of cerebrospinal fluid amyloid beta after systemic administration of M1 muscarinic agonists. Brain Res 2001;905:220-223.

108. Beach TG, Walker DG, Sue LI, et al. Immunotoxin lesion of the cholinergic nucleus basalis causes $\mathrm{A} \beta$ deposition: towards a physiologic animal model of Alzheimer's disease. Curr Med ChemImmun Endoc \& Metab Agents 2003;3:233-243.

109. Oddo S, Caccamo A, Shepherd JD, et al. Triple-transgenic model of Alzheimer's disease with plaques and tangles: intracellular Abeta and synaptic dysfunction. Neuron 2003;39:409-421.

110. Bons N, Rieger F, Drudhomme D, Fisher A, Krause K-H. Microcebus murinus: a useful primate model for human cerebral aging and Alzheimer's disease? Genes Brain Behav 2005;5:120-130.

111. Nordberg A, Hellstrom-Lindhal, Lee M, et al. Chronic nicotine treatment reduces $\beta$-amyloidosis in the brain of a mouse model of Alzhemer's disease (APPsw). J Neurochem 2002;81:655-658.

112. Oddo S, Caccamo A, Green KN, et al. Chronic nicotine administration exacerbates tau pathology in a transgenic model of Alzheimer's disease. Proc Natl Acad Sci U S A 2005; 102: 30463051.

113. Liu L, Ikonen S, Heikkinen T, et al. The effects of long-term treatment with metrifonate, a cholinesterase inhibitor, on cholinergic activity, amyloid pathology, and cognitive function of APP and PS1 doubly transgenic mice. Exp Neurol 2002;173:196-204.

114. Capsoni S, Giannotta S, Stebel M, et al. Ganstigmine and donepezil improve neurodegeneration in AD11 antinerve growth fac- tor transgenic mice. Am J Alzheimers Dis Other Demen 2004; 19:153-160.

115. Van Dam D, Coen K, De Deyn PP. Cognitive evaluation of disease-modifying efficacy of donepezil in the APP23 mouse model for Alzheimer's disease. Psychopharmacology (Berl) 2008; 197:37-43.

116. Ren K, Thinschmidt J, Liu J, et al. The alpha7 nicotinic receptor agonist 4OH-GTS-21 protects axotomized septohippocampal cholinergic neurons in wild type but not amyloid-overexpressing transgenic mice. Neuroscience 2007;145:314-322.

117. Nitsch RM, Deng M, Tennis M, Schenfield D, Growdon JH. The selective muscarinic M1 agonist AF102B decreases levels of total $\mathrm{A} \beta$ in cerebrospinal fluid of patients with Alzheimer's disease. Ann Neurol 2000;48:913-918.

118. Hock C, Madallena A, Raschig A, et al. Treatment with the selective muscarinic M1 agonist talsaclidine decreases cerebrospinal fluid levels of $A \beta 42$ in patients with Alzheimer's disease. Amyloid 2003;10:1-6.

119. Parneti L, Amici S, Lanari A. Cerebrospinal fluid levels of biomarkers and activity of acetylcholinesterase (AChE) and butyrylcholinesterase in Alzheimers's disease patients before and after treatment with different AChE inhibitors. Neurolog Sci 2002;23(suppl 2):s95-s96.

120. Ballard CG, Chalmers KA, Todd C, et al. Cholinesterase inhibitors reduce cortical Abeta in dementia with Lewy bodies. Neurology 2007;68:1726-1729.

121. Perry EK, Kilford L, Lees AJ, Burn DJ, Perry RH. Increased Alzheimer pathology in Parkinson's disease is associated with antimuscarinic drugs. Ann Neurol 2003;54:235-38.

122. Giacobini E, Becker RE. One hundred years after the discovery of Alzheimer's disease. A turning point for therapy? J Alzheimers Dis 2007;12:37-52.

123. Murphy MF, Wilcke SJ, Graham EA, Kurtz NM. First in man experience with NGX267, a selective M1 agonist for disease modification and symptomatic treatment of Alzheimer's disease. Neurodegenerative Dis 2007;4(suppl 1):98. 